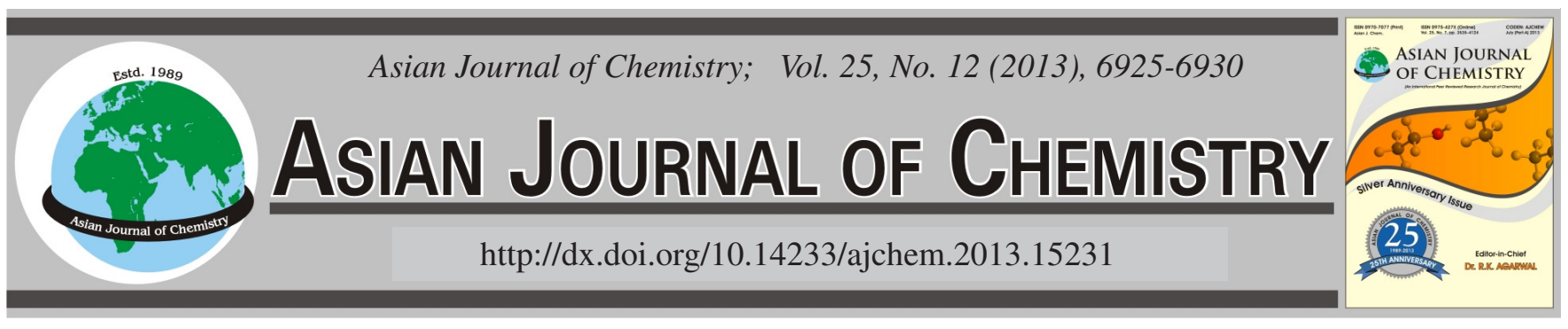

\title{
Optimization and Antioxidant Activity of Flavonoids Extract from Diospyros kaki Thunb. 'Mopan' Pulp
}

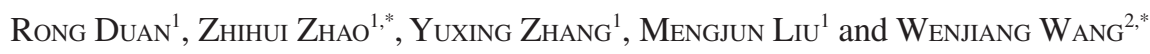

${ }^{1}$ College of Horticulture, Agricultural University of Hebei, Baoding 071001, P.R. China

${ }^{2}$ Mountainous Areas Research Institute, Agricultural University of Hebei, Baoding 071001, P.R. China

*Corresponding authors: E-mail: ijs2008@yahoo.com.cn; wangwj65@126.com

(Received: 29 January 2013;

Accepted: 7 June 2013)

AJC-13602

\begin{abstract}
The ultrasonic-assisted extraction technique for flavonoids from 'Mopan' persimmon pulp was studied and the optimization of technological parameters were obtained by response surface methodology (RSM) with flavonoids extraction rate as index and the antioxidant activities of the extracts were determined. The optimal extraction conditions were using $70 \%$ ethanol as solvent, ratio of liquid to solid 50:1, extraction time of $50 \mathrm{~min}$, ultrasonic power of $450 \mathrm{~W}$ and obtained the extraction rate of $1.57 \%$. The results showed good fits with the proposed model for flavonoids extraction rate $\left(\mathrm{R}^{2}=0.95\right)$. The flavonoids extract prepared by the optimal condition from 'Mopan' persimmon pulp showed high antioxidant activity and a high correlation was obtained between the flavonoids content and the antioxidant activity of 'Mopan' persimmon.
\end{abstract}

Key Words: Ultrasonic-assisted, Response surface methodology, Antioxidant activity, Flavonoids, Extraction rate.

\section{INTRODUCTION}

Persimmon (Diospyros kaki Thunb.) originated in China and has been cultivated over hundreds of years throughout eastern Asia ${ }^{1}$. Based on the statistics of FAO (2010), the production quantity of persimmon in China is about 3.05 million tons, accounting for about $75 \%$ of the total world production (4.06 million tons $)^{2}$. The persimmon has been used as medicine for healing dermatitis, antiwrinkle and treating diabetic, alleviating symptoms of allergy ${ }^{3-6}$. Its fruit has been shown as a rich source of bioactive compounds, including organic acids, polyphenols, carbohydrates, vitamin $\mathrm{C}$, dietary fibers, triterpenic acid, carotenoid and flavonoids $\mathrm{s}^{7-12}$.

Flavonoids are ubiquitous phytochemicals, which are a broad class of low molecular weight, secondary plant phenolics characterized by the flavan nucleus and widely distributed in the leaves, seeds, bark and flowers of plants. To date over 4,000 flavonoids have been identified ${ }^{13}$. Some studies indicate that the flavonoids can be helpful to cure myocardial infarction, ameliorating atherosclerosis and inhibit the production of melanin ${ }^{14-16}$. Most of the interest of flavonoids in healthy effect are their antioxidant and chelating abilities ${ }^{17-22}$.

There are many methods to extract flavonoids, such as soxhlet extraction, heating extraction, boling extraction, refluxing extraction and ultrasound-assisted extraction. Among them, the ultrasonic-assisted extraction is considered to be the more suitable one because it's easy and efficient to use, as well as saving time and money ${ }^{21}$.

Response surface methodology (RSM) was firstly introduced by Box and Draper ${ }^{23}$ and then considered to be an effective statistical method which can optimize complex processes. Several studies on the optimized conditions for the extraction of flavonoids from different sources using response surface methodology have been published ${ }^{19-20,24}$. The main advantage of response surface methodology is the reduced number of experimental trials needed to evaluate multiple parameters and their interactions. Therefore, it is less laborious and less timeconsuming than other approaches required to optimize a process $^{25}$.

In this paper, we studied the Diospyros kaki Thunb. 'Mopan' since it is an excellent cultivar popular in north of China. To our best of knowledge, flavonoids extract and their antioxidant activity of 'Mopan' persimmon have not been investigated before. The objective of this study was to optimize the extraction procedures for improving extraction rate of flavonoids using response surface methodology and evaluate the antioxidant activities of the flavonoids extract obtained from 'Mopan' persimmon pulp in vitro.

\section{EXPERIMENTAL}

Preparation of materials: Samples of 'Mopan' persimmon were collected from Yi County, Baoding, China by the 
end of September 2011. The general properties of the samples were maintained during transportation to the laboratory by keeping them in isothermal boxes containing ice. On arrival, ten intact fruits of the samples in each cultivar were selected to determine the average of fruit weight (167.38 g), shape index (the average vertical diameters of $52.16 \mathrm{~cm}$ and horizontal diameters of $71.33 \mathrm{~cm}$ ) and water content $(84.87 \%)$. After that, the pedicle and peel were removed, then the pulp was cut into small thin pieces and dried at $70{ }^{\circ} \mathrm{C}$ by a DGG-9203A constant temperature drying oven (Senxin experiment corporation, Shanghai, China). Then, the dried persimmon pulp was quickly crushed by a universal high-speed smashing machine (Hongtaiyang Electromechanical Corporation, Yongkang, China). Then the powder was collected and stored in desiccator at room temperature $\left(15-20^{\circ} \mathrm{C}\right)$ until used (less than one month).

2, 2-Diphenyl-1-picrylhydrazyl (DPPH) and 2,4,6-tris (2pyridyl)-s-triazine (TPTZ) were purchased from Sigma Chemical Corporation (St. Louis, MO, USA). Rutin was bought from the National Institute of Control of Pharmaceutical and Biological Products (Beijing, China) and butylated hydroxytoluene (BHT) was purchased from the Chinese Medicine Group Chemical Reagent Corporation (Beijing, China). Methanol which was chromatography grade was purchased from Xingke Biochemical Corporation of Shanghai (Shanghai, China). All other reagents used in the study were purchased from Shanghai Chemicals (Shanghai, China) and were of analytical grade.

Manual extraction procedure: The persimmon powder $(1 \mathrm{~g})$ was conducted in centrifuge tubes $(50 \mathrm{~mL})$ using a KQ500DE model ultrasonic bath (Ultrasonic Instrument Corporation, Kunshan, China) soaked with ethanol solvent (varying ethanol concentration from 30 to $80 \%$, v/v; varying ratio of liquid to solid from 10 to $60 \mathrm{~mL} / \mathrm{g}$ ) for certain time (varying from 20 to $70 \mathrm{~min}$ ) under certain ultrasonic power (varying from 250 to $500 \mathrm{~W}$ ). The extracts were centrifuged at 10000 rpm for 20 min with a CT14RD model centrifuge (Biochemistry Instrument Factory, Shanghai, China), then filtered and the final volume was adjusted to $50 \mathrm{~mL}$ with extraction solvent. The extract was used for determining the total flavonoids.

Experimental design: Response surface methodology was used to optimize flavonoids extraction from 'Mopan' persimmon pulp. A Box-Behnken design (BBD) with four independent variables was used: ratio of liquid to solid $\left(\mathrm{X}_{1}\right)$, ethanol concentration $\left(\mathrm{X}_{2}\right)$, time $\left(\mathrm{X}_{3}\right)$ and ultrasonic power $\left(\mathrm{X}_{4}\right)$. The input range of the selected variables was determined by preliminary response surface methodology experiments. The three independent variables were coded at three levels $(-1,0,1)$, which resulted in an experimental design of 27 experimental points, including four central points to evaluate the pure error. Design Expert.V8.0.6 (Stat-Ease Inc., Minneapolis, USA) was used for designing experiments and statistical data analysis (ANOVA).

Experimental data were analyzed to fit a second order polynomial model as follows:

$$
\mathrm{Y}=\mathrm{b}_{0}+\sum_{\mathrm{i}=1}^{4} \mathrm{~b}_{\mathrm{i}} \mathrm{X}_{\mathrm{i}}+\sum_{\mathrm{i}=1}^{4} \mathrm{~b}_{\mathrm{ii}} \mathrm{X}_{\mathrm{i}}^{2}+\sum_{\mathrm{i}=1}^{3} \sum_{\mathrm{j}=\mathrm{i}+1}^{4} \mathrm{~b}_{\mathrm{ij}} \mathrm{X}_{\mathrm{j}}
$$

where $\mathrm{Y}$ represents the response variables, $\mathrm{b}_{0}$ is a constant, $\mathrm{b}_{\mathrm{i}}$, $b_{i i}$ and $b_{i j}$ are the linear, quadratic and interactive coefficients, respectively. $X_{i}$ and $X_{j}$ are the levels of the independent variables.
The models were predicted through statistical analysis and regression analysis (ANOVA) using Design Expert V8.0.6. Models and regression coefficients were considered significant when P-values were lower than 0.05. The software Design-Expert 8.0.6 (State-Ease Inc., USA) was used to obtain the coefficients of the quadratic polynomial model. The quality of the fitted model was expressed by the coefficient of determination $\mathrm{R}^{2}$ and its statistical significance was checked by an F-test.

Determination of flavonoids content: The total flavonoids content was determined using a slightly modified colorimetric method ${ }^{22}$. $0.3 \mathrm{~mL} \mathrm{NaNO}_{2}$ solution ( $5 \%$, w/v) was added to $1 \mathrm{~mL}$ extract sample. The mixture was allowed to stand for $5 \mathrm{~min}$, then $0.3 \mathrm{~mL} \mathrm{Al}\left(\mathrm{NO}_{3}\right)_{3}$ solution $(10 \%)$ was put in. After standing for $6 \mathrm{~min}, 4 \mathrm{~mL} \mathrm{NaOH}$ solution $(1 \mathrm{~mol} /$ L) was added. The final volume was adjusted to $10 \mathrm{~mL}$ with $30 \%$ ethanol. The mixture was allowed to stand for $15 \mathrm{~min}$ and the absorption was measured at $510 \mathrm{~nm}$ by a UV-3200 spectrophotometer (Mapada, Shanghai, China) against the same mixture without the sample as a blank. The amount of the total flavonoids was expressed as rutin equivalents (mg rutin/g sample) through the calibration curve of rutin. The calibration curve ( $y=1.1927 \mathrm{x}-0.0112$, where $\mathrm{y}$ is absorbance value of sample, $x$ presenting sample concentration) ranged $200-1000 \mu \mathrm{g} / \mathrm{mL}\left(\mathrm{R}^{2}=0.9977\right)$.

Scavenging activity of DPPH radical: The DPPH radical scavenging activities of extract, which was prepared by the optimal ultrasonic-assisted treatment as above, from 'Mopan' persimmon pulp were determined according to the method from Brand-Williams ${ }^{26}$. Briefly, 0.1 mM DPPH in methanol was freshly prepared as DPPH working solution before measurements. Samples were dissolved in extraction solvent to form final concentrations of $0.05,0.10,0.15,0.20$ and 0.25 $\mathrm{mg} / \mathrm{mL}$, respectively. $0.1 \mathrm{~mL}$ samples solution were thoroughly mixed with $5 \mathrm{~mL}$ of DPPH working solution. The mixture was shaken vigorously and allowed to stand for $0.5 \mathrm{~h}$ in the dark and the absorbance was then measured at $517 \mathrm{~nm}$ by a UV-3200 spectrophotometer (Mapada, Shanghai, China). Lower absorbance values of the reaction mixture indicated higher free radical scavenging activity. Methanol was used as the blank control. The percentage of scavenging activity of the free DPPH radical was calculated according to the following equation:

$$
\text { Scavenging activity }(\%)=\left[\left(\mathrm{A}_{0}-\mathrm{A}_{1}\right) / \mathrm{A}_{0}\right] \times 100
$$

where $A_{0}$ is the absorbance of the DPPH solution without addition of the sample, $A_{1}$ is the absorbance of the mixture containing both the sample and DPPH solution after reacting for $0.5 \mathrm{~h}$ in the dark.

Ferric reducing power: The determination of ferric reducing power was performed as described by Benzie and Strain $^{27}$. Prior to analysis, FRAP reagent was prepared by making $10 \mathrm{mmol} / \mathrm{L} \mathrm{TPTZ}-\mathrm{HCl}$ (40 mmol/L HCl), $20 \mathrm{mmol} / \mathrm{L}$ $\mathrm{FeCl}_{3} \cdot 6 \mathrm{H}_{2} \mathrm{O}$ and acetic acid buffer $(0.3 \mathrm{~mol} / \mathrm{L}, \mathrm{pH} 3.6)$ mixed by $1: 1: 10(\mathrm{v} / \mathrm{v} / \mathrm{v}) .120 \mu \mathrm{L}$ sample solution of various concentrations $(0.05,0.10,0.15,0.20$ and $0.25 \mathrm{mg} / \mathrm{mL})$ with the same concentration was added to the solution which contained 360 $\mu \mathrm{L}$ ultra pure water and $3.6 \mathrm{~mL}$ FRAP, respectively. Then the mixture was incubated $37^{\circ} \mathrm{C}$ for $0.5 \mathrm{~h}$. After the mixture stood 
for $1 \mathrm{~h}$ in ordinary temperature, the absorbance was measured at $593 \mathrm{~nm}$ against a blank which used ultra pure water instead of sample solution and with $\mathrm{FeSO}_{4} \cdot 7 \mathrm{H}_{2} \mathrm{O}$ as a standard. Increasing absorbance of the reaction mixture indicates increasing reducing power.

Statistical analysis: In this study, all the experiments were conducted in triplicate. Analysis of variance was performed by ANOVA procedure. $\mathrm{P}$-value $<0.05$ and $\mathrm{P}$-value $<0.01$ were regarded as significant and extremely significant, respectively. The direction and magnitude of the correlation between the variables was quantified by the square of correlation coefficient, R.

\section{RESULTS AND DISCUSSION}

Optimization of ultrasonic-assisted extraction for flavonoids from 'Mopan' persimmon pulp: In this study, ultrasound-assisted extraction was employed for flavonoids from 'Mopan' persimmon pulp. The operational parameters were optimized using Box-Behnken design based on response surface methodology. And the four parameters value, extraction time (40 $\mathrm{min}$ ), ratio of liquid to solid (40:1), ethanol concentration $(60 \%)$ and ultrasonic power $(400 \mathrm{~W})$ were chosen for the optimized experiment as four central points based on single factor tests (data not shown). All experimental data obtained from 27-run-experiment were shown in Table-1.

Experimental values of extraction efficiency of flavonoids (Table-1) were analyzed by multiple regressions to fit the second order regression equation and the regression model in terms of coded factors was predicted as follows:

$$
\begin{aligned}
Y= & 1.044+0.144 X_{1}+0.078 X_{2}+0.102 X_{3}+0.1 X_{4}+ \\
& 0.069 X_{1} X_{2}+0.065 X_{1} X_{3}-0.021 X_{1} X_{4}+0.151 X_{2} X_{3} \\
& +0.036 X_{2} X_{4}+0.088 X_{3} X_{4}-0.093 X_{1}^{2}-019 X_{2}^{2}- \\
& 0.12 X_{3}^{2}+0.166 X_{4}^{2}
\end{aligned}
$$

The coefficients of the above eqn. 3 were calculated using response surface methodology and statistical analysis of the experimental data was used to establish the best-fitted model for the independent variables. The model had a satisfactory levels of adequacy $\left(\mathrm{R}^{2}\right)$ (Table-2). The response values were significantly affected by all the parameters, suggesting that the four parameters were directly related to the flavonoids extraction rate.

The analysis of variance (ANOVA) result of the model was shown in Table-2. A good model performance with the correlation coefficient $\left(\mathrm{R}^{2}\right)$ value of 0.9474 was obtained. The calculated model was able to explain $94.74 \%$ of the result in the case of the flavonoids extraction rate. And the adjusted correlation coefficient of determination $\left(\mathrm{R}_{\mathrm{Adj}}{ }^{2}\right)$ of the equation was 0.8860 , which suggested an excellent correlation between the every two independent variables. The corresponding variables would be more significant if the absolute F-value becomes greater and the P-value becomes smaller ${ }^{28}$. The statistical analysis gave a high F-value (15.4330) and a very low $\mathrm{P}$-value $(\mathrm{P}<0.0001)$, implying the model was significant. $\mathrm{F}$-value for the lack of fit was insignificant $(\mathrm{F}=8.8955)$,

\begin{tabular}{|c|c|c|c|c|c|}
\hline \multicolumn{6}{|c|}{$\begin{array}{c}\text { TABLE-1 } \\
\text { BOX-BEHNKEN DESIGN AND OB }\end{array}$} \\
\hline Run & Ratio of liquid to soild (mL/g) & Ethanol concentration $(\%)$ & Time (min) & Power $(\mathrm{W})$ & ${ }^{\mathrm{a}}$ Extraction rate $(\%)$ \\
\hline Kun & $\mathrm{X}_{1}$ & $\mathrm{X}_{2}$ & $\mathrm{X}_{3}$ & $\mathrm{X}_{4}$ & $\mathrm{Y}$ \\
\hline 1 & $0(40)$ & $1(70)$ & $1(50)$ & $0(400)$ & 1.09 \\
\hline 2 & $0(40)$ & $0(60)$ & $-1(30)$ & $1(450)$ & 0.95 \\
\hline 3 & $0(40)$ & $0(60)$ & $0(40)$ & $0(400)$ & 1.08 \\
\hline 4 & $0(40)$ & $1(70)$ & $0(40)$ & $-1(350)$ & 0.94 \\
\hline 5 & $0(40)$ & $1(70)$ & $0(40)$ & $1(450)$ & 1.29 \\
\hline 6 & $-1(30)$ & $0(60)$ & $-1(30)$ & $0(400)$ & 0.75 \\
\hline 7 & $0(40)$ & $-1(50)$ & $0(40)$ & $1(450)$ & 1.11 \\
\hline 8 & $0(40)$ & $0(60)$ & $1(50)$ & $-1(350)$ & 1.03 \\
\hline 9 & $1(50)$ & $-1(50)$ & $0(40)$ & $0(400)$ & 0.84 \\
\hline 10 & $-1(30)$ & $1(70)$ & $0(40)$ & $0(400)$ & 0.53 \\
\hline 11 & $0(40)$ & $-1(50)$ & $1(50)$ & $0(400)$ & 0.52 \\
\hline 12 & $1(50)$ & $0(60)$ & $1(50)$ & $0(400)$ & 1.12 \\
\hline 13 & $1(50)$ & $0(60)$ & $-1(30)$ & $0(400)$ & 0.84 \\
\hline 14 & $-1(30)$ & $0(60)$ & $0(40)$ & $1(450)$ & 1.06 \\
\hline 15 & $0(40)$ & $0(60)$ & $0(40)$ & $0(400)$ & 1.03 \\
\hline 16 & $0(40)$ & $0(60)$ & $1(50)$ & $1(450)$ & 1.38 \\
\hline 17 & $1(50)$ & $0(60)$ & $0(40)$ & $1(450)$ & 1.26 \\
\hline 18 & $0(40)$ & $-1(50)$ & $-1(30)$ & $0(400)$ & 0.62 \\
\hline 19 & $0(40)$ & $0(60)$ & $-1(30)$ & $-1(350)$ & 0.95 \\
\hline 20 & $1(50)$ & $0(60)$ & $0(40)$ & $-1(350)$ & 1.16 \\
\hline 21 & $-1(30)$ & $0(60)$ & $0(40)$ & $-1(350)$ & 0.88 \\
\hline 22 & $0(40)$ & $0(60)$ & $0(40)$ & $0(400)$ & 1.02 \\
\hline 23 & $0(41)$ & $-1(50)$ & $0(40)$ & $-1(350)$ & 0.90 \\
\hline 24 & $-1(30)$ & $1(50)$ & $0(40)$ & $0(400)$ & 0.58 \\
\hline 25 & $1(50)$ & $1(70)$ & $0(40)$ & $0(400)$ & 1.06 \\
\hline 26 & $-1(30)$ & $0(60)$ & $1(50)$ & $0(400)$ & 0.77 \\
\hline 27 & $0(40)$ & $1(70)$ & $-1(30)$ & $0(400)$ & 0.59 \\
\hline
\end{tabular}
confirming the validity of the model. The results indicated that the model could work well for the prediction of flavonoids extraction from 'Mopan' persimmon.

${ }^{a}$ Flavonoid extraction rate means percentage content of the extracted flavonoids in the studied raw material. 
TABLE-2

ESTIMATED REGRESSION COEFFICIENTS FOR QUADRATIC POLYNOMIAL MODEL AND THE ANALYSIS OF VARIANCE (ANOVA) FOR THE EXPERIMENTAL RESULTS

\begin{tabular}{|c|c|c|c|c|c|c|}
\hline Source $^{a}$ & Sum of squares & $\mathrm{df}^{b}$ & Mean square & F-value & $\mathrm{P}$-value & Significant \\
\hline Model & 1.3471 & 14 & 0.0962 & 15.4330 & $<0.0001$ & $* *$ \\
\hline $\mathrm{X}_{1}$ & 0.2474 & 1 & 0.2474 & 39.6788 & $<0.0001$ & $* *$ \\
\hline $\mathrm{X}_{2}$ & 0.0726 & 1 & 0.0726 & 11.6446 & 0.0052 & $* *$ \\
\hline $\mathrm{X}_{3}$ & 0.1237 & 1 & 0.1237 & 19.8408 & 0.0008 & $* *$ \\
\hline $\mathrm{X}_{4}$ & 0.1195 & 1 & 0.1195 & 19.1654 & 0.0009 & $* *$ \\
\hline $\mathrm{X}_{1} \mathrm{X}_{2}$ & 0.0188 & 1 & 0.0188 & 3.0220 & 0.1077 & \\
\hline $\mathrm{X}_{1} \mathrm{X}_{3}$ & 0.0171 & 1 & 0.0171 & 2.7410 & 0.1237 & \\
\hline $\mathrm{X}_{1} \mathrm{X}_{4}$ & 0.0018 & 1 & 0.0018 & 0.2807 & 0.6059 & \\
\hline $\mathrm{X}_{2} \mathrm{X}_{3}$ & 0.0912 & 1 & 0.0912 & 14.6262 & 0.0024 & $* *$ \\
\hline $\mathrm{X}_{2} \mathrm{X}_{4}$ & 0.0052 & 1 & 0.0052 & 0.8292 & 0.3804 & \\
\hline $\mathrm{X}_{3} \mathrm{X}_{4}$ & 0.0311 & 1 & 0.0311 & 4.9955 & 0.0452 & * \\
\hline $\mathrm{X}_{1}^{2}$ & 0.0458 & 1 & 0.0458 & 7.3520 & 0.0189 & $*$ \\
\hline $\mathrm{X}_{2}{ }^{2}$ & 0.1927 & 1 & 0.1927 & 30.9126 & 0.0001 & $* *$ \\
\hline $\mathrm{X}_{3}^{2}$ & 0.0774 & 1 & 0.0774 & 12.4181 & 0.0042 & $* *$ \\
\hline $\mathrm{X}_{4}^{2}$ & 0.1466 & 1 & 0.1466 & 23.5166 & 0.0004 & $* *$ \\
\hline Residual & 0.0748 & 12 & 0.0062 & & & \\
\hline Lack of fit & 0.0732 & 10 & 0.0073 & 8.8955 & 0.1052 & \\
\hline Pure error & 0.0016 & 2 & 0.0008 & & & \\
\hline Cor total & 1.4220 & 26 & & & & \\
\hline $\mathrm{R}_{\mathrm{Adj}}^{2}=0.886$ & $\mathrm{R}^{2}=0.9474$ & & & & & \\
\hline
\end{tabular}

It can be seen from Fig. 1 that the 3D response surface plots which express the effects of all independent variables on the flavonoids extraction rate were provided by varying two variables under investigation simultaneously while the other two were in their central level value within the experimental range.

Fig. 1a, b and c showed the effects made by ratio of liquid to solid with each of the other three factors on the flavonoids extraction rate. It implied that with the ratio of liquid to solid increasing from 30:1 to 45:1 the extraction ratio increased and became into constant at the following ratio from 45:1 to 50:1. Fig. 1a, $d$ and e represented the effects of ethanol concentration on the extraction rate with each of the other three factors. The extraction rate increased with the increase of ethanol concentration up to $65 \%$ while decreased in higher ethanol concentrations (65-70\%). This effect may be due to the change of solvent polarity as ethanol concentration increases, which would be unsuitable for extracting flavonoids. The effects of extraction time with each of the other three factors on the flavonoids extraction rate were shown by the Fig. 1b, d, f. It is obvious that the shorter extraction time resulted in the lower yield, the extraction rate of flavonoids increased to a certain value with increasing extraction time from 30 to $45 \mathrm{~min}$ and thereafter decreased. As the extraction time prolongs, the chemical decomposition of bioactive compound present in extract may occur, resulting in a decrease in extraction yield. The effects of ultrasonic power interaction with each of the other three factors on the extraction yield of flavonoids were shown in Fig. 1c, e, f. The extraction rate of flavonoids raised quickly when the ultrasonic power increased from 350 to 450 $\mathrm{W}$. This is possible that the increase in ultrasonic power could accelerate the mass diffusion which can increase the contact area and improve the extraction rate.

The optimized results can be predicted as follows: the maximum extraction rate of flavonoids by ultrasonic-assisted extraction reached $1.62 \%$ by using $68.73 \%(\mathrm{v} / \mathrm{v})$ ethanol and $50: 1(\mathrm{~mL} / \mathrm{g})$ liquid to solid ratio for $50 \mathrm{~min}$ with the ultrasonic power of $450 \mathrm{~W}$. However, considering the operability in practical, we made slightly modify as follows: $70 \%(\mathrm{v} / \mathrm{v})$ ethanol and $50: 1(\mathrm{~mL} / \mathrm{g})$ ratio of liquid to solid for $50 \mathrm{~min}$ with the ultrasonic power of $450 \mathrm{~W}$.

To validate the adequacy of the model, a verification experiment was performed under adjusted optimal conditions mentioned above and obtained flavonoids yield of $1.57 \%$ by three replicated experiments.

Scavenging Activity on DPPH radical: The DPPH free radical is a stable free radical with an absorption peak at 517 $\mathrm{nm}$ has been widely accepted as a tool for estimating the free radical-scavenging activity of antioxidant ${ }^{29,30}$. The DPPH radical can be eliminated when it come across the material which can provide hydrogen proton such as the antioxidants. In present DPPH experiment, the antioxidants could clear the stable DPPH free radical with the colour fades from dark purple to light yellow.

The result of DPPH free radical-scavenging ability of 'Mopan' persimmon pulp extract was shown in Fig. 2. As can be seen from Fig. 2, a strong correlation was observed between the antioxidant activity and the flavonoids content of 'Mopan' in persimmon in this study $\left(\mathrm{R}^{2}=0.9429\right)$. The scavenging DPPH radical increased from 26.52 to $93.07 \%$, when the flavonoids at concentrations of 0.05 to $0.25 \mathrm{mg} / \mathrm{mL}$.

Ferric reducing power: It is known that at low $\mathrm{pH}$, when a ferric-tripyridyltriazine $\left(\mathrm{Fe}^{3+}\right.$-TPTZ) complex is reduced to the ferrous $\left(\mathrm{Fe}^{2+}\right)$ form by reaction with reductants (antioxidants), an intense blue colour with an absorption maximum at $593 \mathrm{~nm}$ develops. During present ferric reducing power assay, the presence of flavonoids in the tested samples would present as the antioxidant. Then, with excess Fe(III) is used, the more production of $\mathrm{Fe}^{3+}$, the higher reducing ability of the flavonoids. The correlation observed with the antioxidant activity values 

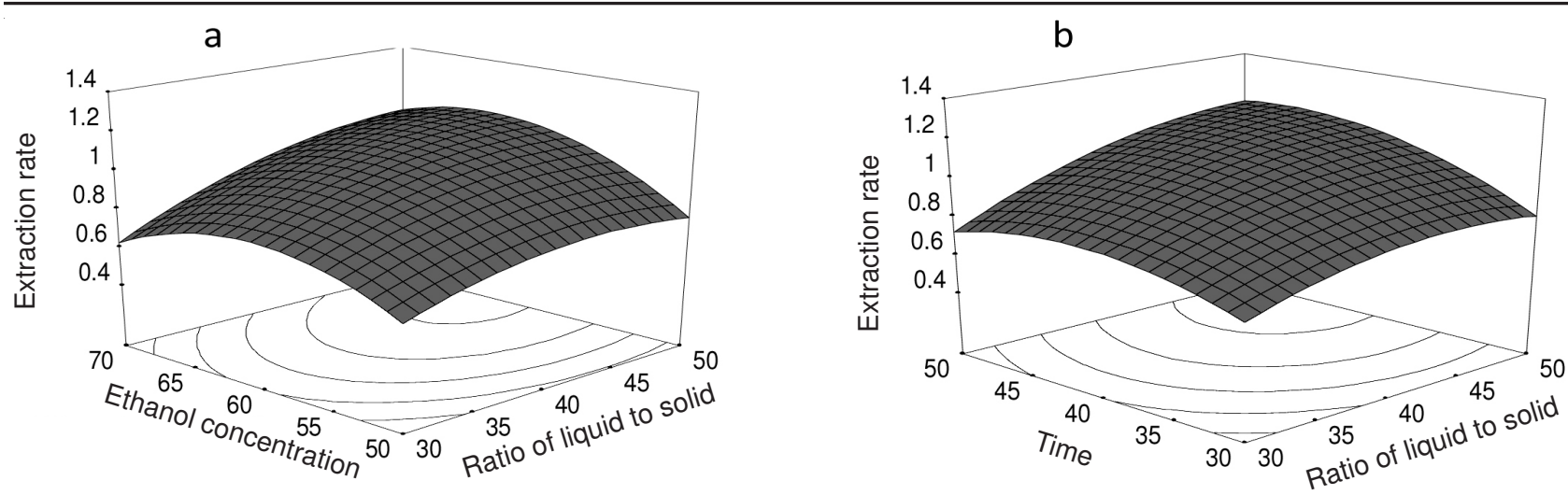

C
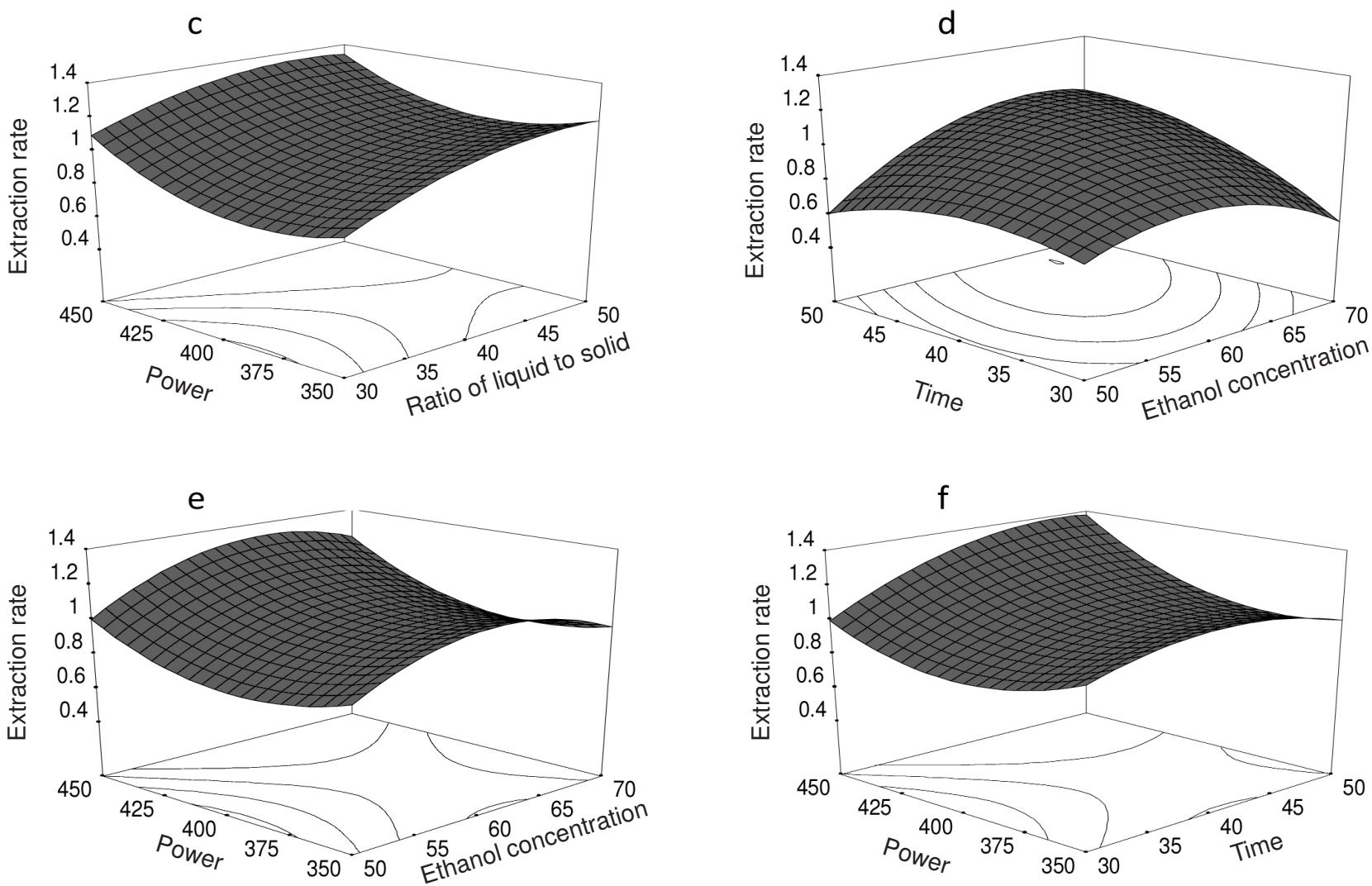

Fig. 1. Response surface plot for flavonoids extraction of the effect of (a) varying ethanol concentration and ratio of liquid to solid, (b) varying time and ratio of liquid to solid, (c) varying power and ratio of liquid to solid, (d) varying time and ethanol concentration, (e) varying power and ethanol concentration and (f) varying power and time

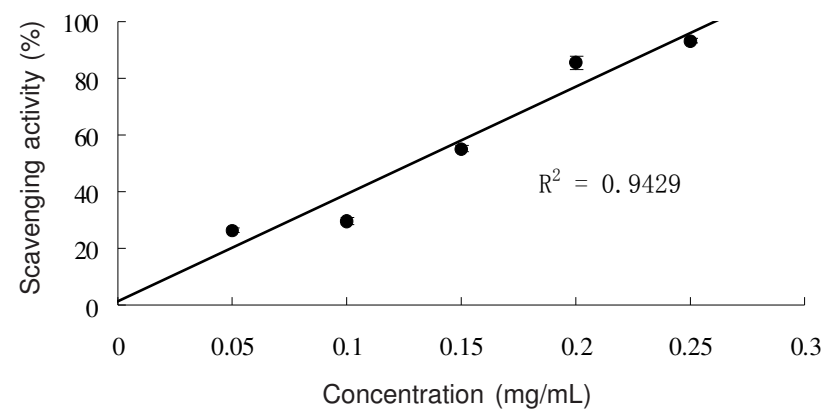

Fig. 2. Correlation between Scavenging activity of 'Mopan' persimmon pulp and flavonoids content. $(n=3$, mean \pm SD)

measured by the ferric reducing power method was even stronger $\left(\mathrm{R}^{2}=0.9604\right)$ than that measured by the DPPH method $\left(\mathrm{R}^{2}=0.9429\right)$ (Fig. 3). The formation of $\mathrm{Fe}^{2+}$ ranged from

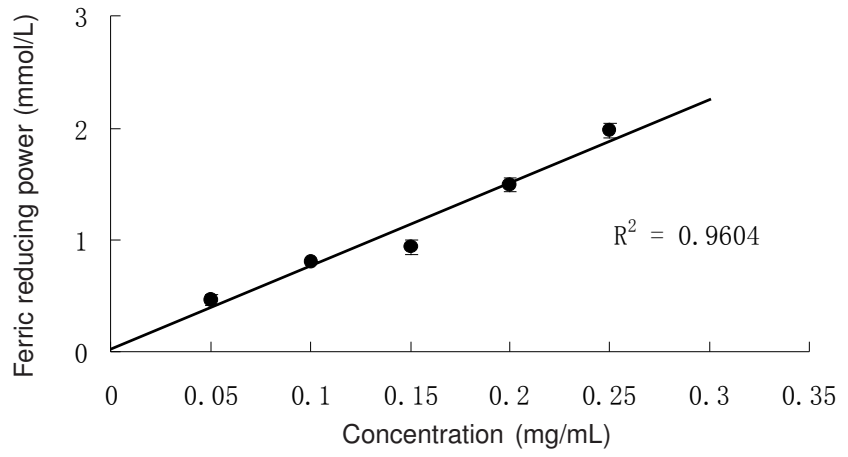

Fig. 3. Correlation between ferric reducing power of 'Mopan' persimmon pulp and flavonoids content $(n=3$, mean \pm SD)

0.46 to $1.98 \mathrm{mmol} / \mathrm{L}$ when the flavonoids concentrations varied from 0.05 to $0.25 \mathrm{mg} / \mathrm{mL}$. Present data suggest that the extract 
of 'Mopan' persimmon pulp have a significant effect on the reducing activity.

\section{Conclusion}

In this study, the optimal ultrasonic-assistanted extraction of flavonoids from 'Mopan' persimmon pulp was investigated with a four-variable, three-level Box-Behnken experiment design based on response surface methodology. All the parameters had highly significant effect on the response value. The optimal practical flavonoids yield of $1.57 \%$ by ultrasonicassisted extraction was obtained with the optimum extraction parameters: ratio of liquid to solid 50:1, enthanol concentration at $70 \%$, extraction time of $50 \mathrm{~min}$ and $450 \mathrm{~W}$ ultrasonic power. The experiment value for yield of the flavonoids was well consistent with the predicted value (the yield of $1.62 \%$ ).

A very high correlation was observed between the antioxidant activity and flavonoids content, which suggests that the flavonoids had a positive effect on the antioxidant activity. What's more, based on the results of DPPH radical scavenging activity and Ferric reducing power experiments, the extract of 'Mopan' persimmon pulp exerted significant antioxidant activities. According to this study, the flavonoids extract from 'Mopan' persimmon pulp may be developed to an effective natural antioxidant as function foods.

\section{ACKNOWLEDGEMENTS}

The authors gratefully acknowledged the financial support by Special Fund for Agro-Scientific Research in the Public Interest of China (201203047) and The Central Government Demonstration and Promotion Fund of Forestry Science \& Technology (Ji TG[2011]003).

\section{REFERENCES}

1. Y.L. Xue, T. Miyakawa, Y. Hayashi, K. Okamoto, F. Hu, N. Mitani, K. Furihata, Y. Sawano and M. Tanokura, J. Agric. Food Chem., 59, 6011 (2011).

2. FAO, http://faostat3.fao.org Assessed on 20 December (2012).

3. M. Kotani, M. Matsumoto, A. Fujita, S. Higa, W. Wang, M. Suemura, T. Kishimoto and T. Tanaka, J. Allergy Clin. Immun., 106, 159 (2000).
4. B.J. Eunan, J.H. Kwak, J.M. Park., J.Y. Lee, T.S. Park, J.T. Lee, J.H. Son, C.R. Jo and M.W. Byun, Dermatol. Surg., 37, 848 (2005).

5. T. Yokozawa, Y.A. Kim, H.Y. Kim, Y.A. Lee and G.I. Nonaka, Food Chem. Toxicol., 45, 1979 (2007).

6. T. Itoh, K. Ohguchi, C. Nakajima, M. Oyama, M. Iinuma, Y. Nozawa, Y. Akao and M. Ito, Food Chem., 126, 289 (2011).

7. H.G. Daood, P. Biacs and B. Czinkotai, Food Chem., 45, 151 (1992).

8. Y. Ittah, Food Chem., 48, 25 (1993).

9. P.M. Li, G.R. Du and F.W. Ma, Sci. Hortic-Amsterdam, 129, 710 (2011).

10. S. Sakanaka, Y. Tachibana and Y. Okada, Food Chem., 89, 569 (2005).

11. M.S. Akter, M. Ahmed and J.B. Eun, Int. J. Food Sci. Tech., 45, 1258 (2010).

12. C. Zhou, D. Zhao, Y. Sheng, J. Tao and Y. Yang, Molecules, 16, 624 (2011).

13. K.E. Heim, A.R. Tagliaferro and D.J. Bobilya, J. Nutr. Biochem., 13, 572 (2002).

14. T. Ishikawa, M. Suzukawa, T. Ito, H. Yoshida, M. Avaori, M. Nishiwaki, A. Yonernura, Y. Hara and H. Nakamura, Am. J. Clin. Nutr., 66, 261 (1997).

15. J.M. Geleijnse, L.J. Launer, D. Kuip, A. Hofman and J.C. Witteman, Am. J. Clin. Nutr., 75, 880 (2002).

16. K. Ouguchi, C. Nakajima, M. Oyama, M. Iinuma, T. Itoh, Y. Akao, Y. Nozawa and M. Ito, Biol. Pharm. Bull., 33, 122 (2010).

17. P.C.H. Hollman, J.M.P. van Trijp, M.N.C.P. Buysman, M.S. v.d. Gaag, M.J.B. Mengelers, J.H.M. de Vries and M.B. Katan, Febs. Lett., 418, 152 (1997).

18. J.E. Brown, H. Khodr, R.C. Hider and C.A. Rice-Evans, Biochem. J., 330, 1173 (1998)

19. W. Huang, A. Xue, H. Niu, Z. Jia and J. Wang, Food Chem., 114, 1147 (2009).

20. G. Zhang, L. He and M. Hu, Innov. Food Sci. Emerg., 12, 18 (2011).

21. H. Li, B. Chen and S.Z. Yao, Ultrason. Sonochem., 12, 295 (2005).

22. Z. Jia, M. Tang and J. Wu, Food Chem., 64, 555 (1999).

23. G.E.P. Box and N.R. Draper, Empirical Model Building and Response Surface, John Wiley \& Sons. Inc., Canada (1987).

24. G.D.S.C. Borges, F.G.K. Vieira, C. Copetti and L.V. Gonzaga, R. Fett. Food Res. Int., 44, 708 (2011).

25. K. Zhong and Q. Wang, Carbohyd. Polym., 80, 19 (2010).

26. W. Brand-Williams, M.E. Cuvelier and C. Berset, Lebensm-wiss. Technol., 28, 25 (1995).

27. I.F.F. Benzie and J.J. Strain, Anal. Biochem., 239, 70 (1996).

28. J.H. Xie, M.Y. Shen, M.Y. Xie, S.P. Nie, Y. Chen, C. Li, D.F. Huang andY.X. Wang, Carbohyd. Polym., 89, 177 (2012).

29. J. Tabart, C. Kevers, A. Sipel, J. Pincemail, J. Defraigne and J. Dommes, Food Chem., 105, 1268 (2007).

30. H.H. Wijngaard and N. Brunton, J. Food Eng., 96, 134 (2010). 